\section{The gift of time}

A middle-aged woman with a complaint of lower abdominal pain presented herself to our clinic after walking two hours from an adjacent village.

She was one of some 300 patients that our medical team saw daily in the clinics in a province of India.

The woman's brightly coloured clothing was a stark contrast to her pale lips and face.

With the aid of a translator, she explained that her pain had begun that morning, rather suddenly in her lower back and abdomen.

She lay down on the examination table and lifted the many layers to reveal her thin frame. One barely needed to lay hands on her belly to feel the large and ominous pulsatile mass that was present.

She was hypotensive, with a systolic blood pressure in the 80 s and tachycardic.

We told her that we thought she had a leaking Triple A (abdominal, aortic aneurism) and that she needed to go to the hospital in the closest town, a oneour drive.

We explained that even if she made it to the hospital, her condition may be beyond their capabilities.

A discussion ensued and she appeared to understand the nature of her condition. She told us she wanted to return home to organize her things and would return to the clinic the following day to take the ride we were offering to the hospital.

Her mind was made up and she politely left.

I remember thinking we had travelled all the way here - 16 hours by plane, four hours by rail and 12 hours

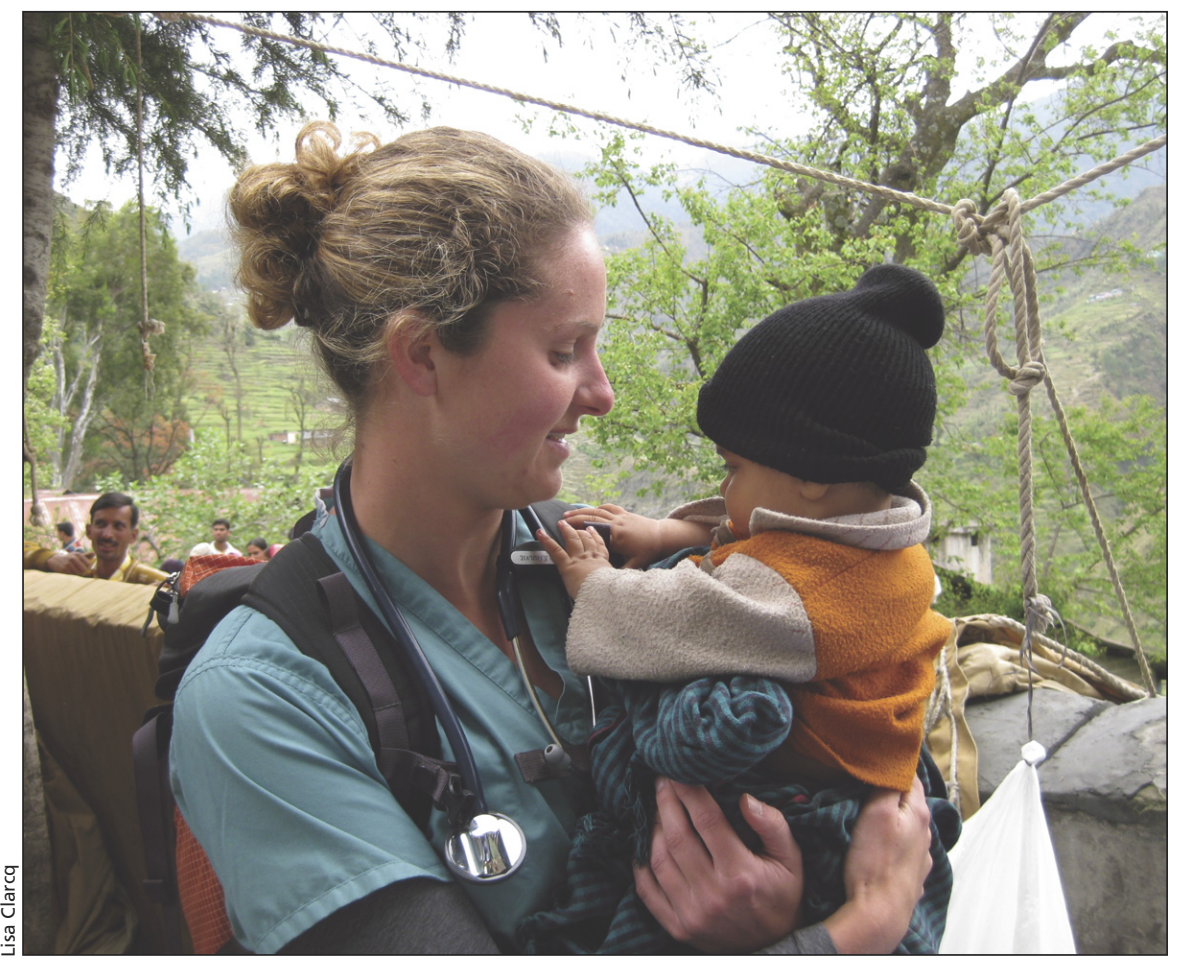

Dr. Kelly Ogilvie holds a young patient outside a clinic in a province of India.

by truck - with our knowledge and skills, yet there wasn't anything any of us could do in the clinic to help this woman.

But later that day, I thought, maybe there was something we did offer her - we gave her the chance to say goodbye, tend to her family and to her things. We gave her the chance and the choice to go home.

Yearly, hundreds of health care providers travel all over the world to provide the skills, time and manpower to see and help countless patients. I am now proud to be one of them. But I've learned that one of the strongest contributions we make sometimes is not our skills or antibiotics, but the knowledge to tell someone that it's time. - Kelly Ogilvie MD, Ottawa, Ont.

DOI:10.1503/cmaj.109-3047

CMAJ invites contributions to "Dispatchs from the medical front," in which physicians and other health care providers offer eyewitness glimpses of medical frontiers, whether defined by location or intervention. Submissions, which must run a maximum 700 words, should be forwarded to:wayne.kondro@cmaj.ca 